\title{
Small-molecule-hosting nanocomposite films with multiple bacteria-triggered responses
}

\author{
Svetlana Pavlukhina ${ }^{1}$, Iryna Zhuk ${ }^{1}$, Almagul Mentbayeva ${ }^{2}$, Emily Rautenberg ${ }^{3}$, Wei Chang ${ }^{1}$, Xiaojun $\mathrm{Yu}^{1}$, \\ Betsy van de Belt-Gritter ${ }^{4}$, Henk J Busscher ${ }^{4}$, Henny C van der $\mathrm{Mei}^{4}$ and Svetlana A Sukhishvili ${ }^{1}$
}

We report $\mathrm{pH} /$ bacteria-responsive nanocomposite coatings with multiple mechanisms of antibacterial protection that include the permanent retention of antimicrobials, bacteria-triggered release of antibiotics and bacteria-induced film swelling. A novel small-molecule-hosting film was constructed using layer-by-layer deposition of montmorillonite (MMT) clay nanoplatelets and polyacrylic acid (PAA) components, both of which carry a negative charge at neutral $\mathrm{pH}$. The films were highly swollen in water, and they exhibited major changes in swelling as a function of $\mathrm{pH}$. Under physiologic conditions $(\mathrm{pH} 7.5,0.2 \mathrm{M} \mathrm{NaCl}$ ), hydrogel-like MMT/PAA films took up and sequestered $\sim 45 \%$ of the dry film matrix mass of the antibiotic gentamicin, causing dramatic film deswelling. Gentamicin remained sequestrated within the films for months under physiologic conditions and therefore did not contribute to the development of antibiotic resistance. When challenged with bacteria (Staphylococcus aureus, Staphylococcus epidermidis or Escherichia coli), the coatings released PAA-bound gentamicin because of bacteria-induced acidification of the immediate environment, whereas gentamicin adsorbed to MMT nanoplatelets remained bound within the coating, affording sustained antibacterial protection. Moreover, an increase in film swelling after gentamicin release further hindered bacterial adhesion. These multiple bacteria-triggered responses, together with nontoxicity to tissue cells, make these coatings promising candidates for protecting biomaterial implants and devices against bacterial colonization.

NPG Asia Materials (2014) 6, e121; doi:10.1038/am.2014.63; published online 29 August 2014

\section{INTRODUCTION}

Polymer nanocomposites uniquely combine the properties of inorganic and organic components that is central to the development of novel advanced materials. The naturally occurring smectite clays, which are chemically and thermally stable and biocompatible, are attractive nanocomposites. Exfoliated clay nanoplatelets strongly impact the mechanical, transport, optical, fire retardant and gas barrier properties of nanocomposite materials. ${ }^{1,2}$ For many biomedical applications, however, hydrophilic rather than hydrophobic nanocomposites are of great interest, and responsive properties are essential. ${ }^{3}$ Reports on responsive hydrophilic nanocomposites are rare, and those few known to us advantageously use the complementary properties of temperature/pH-responsive polymers and clay nanosheets to yield environmentally controlled free-standing materials. ${ }^{4}$

A promising way to leverage the favorable properties of hydrophilic-responsive nanocomposites on surfaces is to use the layer-by-layer (LbL) technique to construct 'smart' surface coatings. ${ }^{5}$ To construct clay-containing LbL films, electrostatic interactions of positively charged polymers with negatively charged basal planes of silicate nanosheets, ${ }^{6,7}$ neutral polymer/nanoplatelet hydrogen bonding $^{8}$ or a combination of the two have been explored. ${ }^{9}$
Nanoplatelets of smectite family clays such as montmorillonite (MMT), which have a high aspect ratio and a high in-plane elastic modulus, can be included within LbL films at a much higher percentage than their clay-polymer bulk counterparts, resulting in ultrathin LbL assemblies with exceptional mechanical ${ }^{8}$ and fire retardant/oxygen barrier properties. ${ }^{10,11}$ However, the response properties of nanocomposite LbL constructs, which are central to the biomedical applications of these materials, have remained largely unexplored. We have recently reported on highly swollen, hydrogellike nanocomposite LbL films composed of neutral, temperatureresponsive polymer and MMT nanoplatelets. ${ }^{12}$ Although these surface-bound hydrogels demonstrated large-amplitude reversible swelling/deswelling transitions as a function of temperature, these films were not suitable matrices to host small molecules for controlled release. Organoclays trapped within a polyelectrolyte capsule wall have been used to endow responsiveness to clay-containing LbL assemblies. ${ }^{13}$ Here, we sought to explore assemblies of unmodified MMT platelets and a weak polycarboxylic acid that could be directly assembled within robust LbL films. These assemblies served as 'smart' matrices that could host and release small bioactive molecules in response to bacterial stimuli.

${ }^{1}$ Department of Chemistry, Chemical Biology and Biomedical Engineering, Stevens Institute of Technology, Hoboken, NJ, USA; ${ }^{2}$ School of Engineering, Nazarbayev University, Astana, Kazakhstan; ${ }^{3}$ Department of Computer Science \& Department of Visual Arts and Technology, Stevens Institute of Technology, Hoboken, NJ, USA and ${ }^{4}$ University of Groningen and University Medical Center Groningen, Department of Biomedical Engineering, Groningen, The Netherlands

Correspondence: Professor SA Sukhishvili, Department of Chemistry, Chemical Biology and Biomedical Engineering, Stevens Institute of Technology, 507 River Street, Hoboken, NJ 07030, USA.

E-mail: ssukhish@stevens.edu

Received 18 April 2014; revised 27 May 2014; accepted 29 May 2014 
Our clay-polyacid surface coatings present a unique combination of properties, including (1) like charge of film components and extremely high degrees of film swelling, (2) $\mathrm{pH}$ control of film swelling and (3) the availability of polyacid and clay platelet-binding sites for $\mathrm{pH}$-dependent and $\mathrm{pH}$-independent antibiotic binding, respectively. We demonstrate that these nanocomposite coatings are ideal matrices for hosting functional molecules, including antibiotics with multiple functionalities to protect against bacterial colonization.

Bacterial colonization of surfaces, especially when such colonization progresses to biofilms, reduces the effectiveness of antibiotic therapies $^{14}$ and presents a serious problem in biomaterial implants and device surgery. To alleviate this problem, a number of approaches ${ }^{15}$ have been proposed to modify surfaces with polymer coatings that are anti-adhesive, ${ }^{16,17}$ kill bacteria on contact, ${ }^{18}$ elute antimicrobial compounds with time ${ }^{19}$ or provide antibacterial protection through enzymatic degradation of a biofilm matrix. ${ }^{20}$ The assembly of surface coatings via LbL deposition enables the inclusion of a broad range of components within conformal coatings and has been explored to construct contact-killing ${ }^{21}$ or release-killing films. ${ }^{22}$

Owing to the complexity of bacterial and biofilm metabolism and the limitations of each individual antibacterial defense path, reliable antibacterial protection of surfaces remains elusive. Therefore, new multifunctional coatings are being explored that combine releasekilling and contact-killing capabilities. ${ }^{23,24}$ Moreover, antibacterial surfaces have been designed that can respond to light or $\mathrm{pH}^{25,26}$ The present study goes beyond this prior work by describing a new type of coating that was engineered to combine permanent, contactkilling protection with bacteria-triggered, on-demand release of antimicrobials. By exploring clay-containing nanocomposites rather than all-polymer films as matrices to host an antibiotic, we were able to prevent low-level tail release of antibiotics that consequently minimizes the development of antibiotic resistance. Simultaneously, we combined antibiotic retention with a bacteria-triggered release mechanism, a concept recently introduced by our group, ${ }^{26,27}$ such that antimicrobials remain sequestered within coatings until bacteria approach the surface. In our model, the secretion of lactic acid by staphylococci ${ }^{28}$ or acetic acid by Escherichia coli ${ }^{29}$ locally acidifies the environment to induce a $\mathrm{pH}$-triggered release of antibiotics. Similarly, antibiotic-free 'self-defensive' coatings have been developed for use with a different trigger, that is, a bacteria-secreted enzyme. ${ }^{30}$ Although we have previously demonstrated the concept of 'self-defense' antibacterial protection using a strongly charged, toxic peptide, a clinically relevant cationic antibiotic for local release, such as gentamicin, could not be sufficiently retained within all-polymer gel films and microgels in $0.2 \mathrm{M}$ salt solutions at $\mathrm{pH} 7.5 .^{26}$ Here, by using a clay-polymer nanocomposite matrix, we were able to achieve a combination of strong antibiotic retention with bacteria-triggered release under physiologic conditions.

\section{MATERIALS AND METHODS}

\section{LbL film deposition}

All chemicals were used as purchased without any further purification. Milli-Q system (Millipore, Billerica, MA, USA) filtered water with a resistivity of $18.2 \mathrm{M} \Omega$ was used in all experiments. Silicon (110) wafers were prime grade, p-type with boron dopant, $525 \pm 25 \mu \mathrm{m}$ thick, with a native oxide layer $\sim 2 \mathrm{~nm}$ thick and were purchased from Cemat Silicon SA (Warszawa, Poland). The wafers were cut with a Fletcher steel wheel glass cutter (Fletcher, East Berlin, CT, USA). The silicon wafers were precleaned under a quartz UV lamp for at least $2 \mathrm{~h}$, soaked in concentrated sulfuric acid for $1 \mathrm{~h}$ and then carefully rinsed with Milli-Q water. The silicon wafers were then dried under a flow of nitrogen. To enhance the attachment of multilayers to the silica surface, a layer of branched poly(ethyleneimine) $\left(M_{w} 65 \mathrm{kDa}\right.$, Sigma Aldrich, St Louis, MO, USA) was deposited as a precursor. Poly(ethyleneimine) was allowed to adsorb at the surface from $0.2 \mathrm{mg} \mathrm{ml}^{-1}$ polymer solutions in $0.01 \mathrm{M}$ phosphate buffer (monobasic and dibasic sodium phosphate, Sigma Aldrich) at $\mathrm{pH}$. The poly(ethyleneimine) deposition step was followed by rinsing the surface with a buffer solution of the same $\mathrm{pH}$ value or by centrifuging and redispersing silica particles in a fresh $0.01 \mathrm{~m}$ phosphate buffer solution (PBS) at $\mathrm{pH}$ 5. For LbL deposition of particles, monodisperse silica particles with a diameter of $4.0 \pm 0.2 \mu \mathrm{m}$ were purchased from Polysciences Inc. (Warrington, PA, USA) as $10 \%$ dispersions in water. These dispersions were diluted with water to $0.1 \%$ before depositing the nanocomposite multilayers. Deposition of MMT/polyacrylic acid (PAA) multilayers on both flat and particulate substrates was performed using $0.2 \mathrm{mg} \mathrm{ml}^{-1}$ PAA $\left(M_{w} 450 \mathrm{kDa}\right.$, Scientific Polymer Products Inc. Ontario, NY, USA) and $\sim 0.4-0.5 \mathrm{mg} \mathrm{ml}^{-1} \mathrm{MMT}$ (Cloisite $\mathrm{Na}^{+}$from Southern Clay Products Inc., Gonzales, TX, USA) aqueous solutions at pH 2.2. A stock solution of MMT $\left(5 \mathrm{gl}^{-1}\right)$ was prepared at least 2 weeks in advance. The MMT deposition solutions were prepared by diluting a stock MMT solution 10-fold with water, followed by sonication overnight. During multilayer deposition, PAA and MMT were allowed to adsorb for $6 \mathrm{~min}$. For silica dispersions, the adsorption and rinsing steps were performed under continuous shaking. After each deposition step, three rinsing/centrifugation cycles were performed using water at $\mathrm{pH}$ 2.2. All films contained MMT as an outermost layer.

\section{Incorporation of gentamicin within MMT/PAA films}

To load an antibacterial agent, MMT/PAA films were exposed to gentamicin solutions $\left(0.2 \mathrm{mg} \mathrm{ml}^{-1}\right.$ in $0.2 \mathrm{M} \mathrm{NaCl}, 0.01 \mathrm{M}$ phosphate buffer at $\left.\mathrm{pH} 7.5\right)$ for at least $30 \mathrm{~min}$ to achieve complete absorption of gentamicin within the films.

\section{The $\mathrm{pH}$-triggered release of gentamicin from MMT/PAA films} To study the $\mathrm{pH}$-triggered release of gentamicin from MMT/PAA hydrogel films, the loaded nanocomposite matrices were exposed to $0.01 \mathrm{M}$ phosphate buffer solutions containing $0.2 \mathrm{M} \mathrm{NaCl}$ with the $\mathrm{pH}$ set at various values between 3.5 and 7.5

\section{Colorimetric assay for gentamicin quantification}

To generate a calibration curve, $0.5-\mathrm{ml}$ aliquots of gentamicin solutions at concentrations ranging from 0.01 to $0.5 \mathrm{mg} \mathrm{ml}^{-1}$ were mixed with $0.15 \mathrm{ml}$ $1.25 \%(\mathrm{w} / \mathrm{v})$ aqueous ninhydrin solution. The reaction was allowed to proceed for $15 \mathrm{~min}$ in boiling water before absorption measurements at $400 \mathrm{~nm}$.

\section{Bacterial strains and growth conditions}

Staphylococcus aureus ATCC 12600, Staphylococcus epidermidis ATCC 14990 and E. coli ATCC 25922 were purchased from the American Type Culture Collection (ATCC, Wesel, Germany). Each strain was taken from a frozen stock (stored at $-80^{\circ} \mathrm{C}$ ), streaked on an agar plate and incubated overnight at $37^{\circ} \mathrm{C}$. E. coli was grown on an agar plate with brain-heart infusion broth (Oxoid, Basingstoke, UK), and S. aureus ATCC 12600 and S. epidermidis ATCC 14990 were grown on a tryptic soy broth (Oxoid) agar plates. After incubation, the plates were stored at $4{ }^{\circ} \mathrm{C}$ for up to 1 month. Precultures of bacteria were made by inoculating a single bacterial colony in $10 \mathrm{ml}$ of brain-heart infusion broth for E. coli and tryptic soy broth for S. aureus and S. epidermidis and incubated at $37^{\circ} \mathrm{C}$ in ambient air for $24 \mathrm{~h}$. These precultures were sonicated at $30 \mathrm{~W}$ (Vibra Cell model 375, Sonics and Materials Inc., Newtown, CT, USA) on ice ( 3 times for $10 \mathrm{~s}$ each with $30 \mathrm{~s}$ between intervals), counted using a Bürker Türk counting chamber (VWR International BV, Amsterdam, The Netherlands) and then diluted with the appropriate growth medium to the desired concentration.

\section{Petrifilm aerobic plate count procedure}

All Petrifilms (3M Microbiology, St Paul, MN, USA) were swollen with $1 \mathrm{ml}$ of sterile demineralized water for $30 \mathrm{~min}$. The Petrifilm cover with the swollen agar layer was peeled back, and the $2.5 \times 2.5 \mathrm{~cm}$ wafers were placed in the Petrifilm with the coated side facing up. A pipet was used to place a $25 \mu \mathrm{l}$ droplet of bacterial suspension (concentrations of $4 \times 10^{3}, 1.6 \times 10^{4}, 4 \times 10^{5}$, 
$4 \times 10^{7}$ and $2 \times 10^{10}$ bacteria per $\mathrm{ml}$, corresponding to bacterial challenges of $16,64,1.6 \times 10^{3}, 1.6 \times 10^{5}$ and $8 \times 10^{7}$ bacteria per $\mathrm{cm}^{2}$, respectively) on the MMT/PAA-coated surface, the Petrifilm cover with the agar layer was closed to disperse the droplet uniformly across the entire surface and the system was incubated at $37^{\circ} \mathrm{C}$ for $48 \mathrm{~h}$ before enumeration of the colony-forming units. For control experiments with MMT/gentamicin films, bacterial concentrations of $2 \times 10^{4}, 4 \times 10^{4}$ and $4 \times 10^{5}$ bacteria per $\mathrm{ml}$, corresponding to bacterial challenges of 80,160 and $1.6 \times 10^{3}$ bacteria per $\mathrm{cm}^{2}$, were used.

\section{Flow chamber experiments}

Bacterial precultures were used to inoculate $200 \mathrm{ml}$ of the appropriate growth medium and grown for $16 \mathrm{~h}$. The bacteria were harvested by centrifugation at $5000 \times g$ for $5 \mathrm{~min}$ at $10^{\circ} \mathrm{C}$ and washed twice in sterile PBS. The bacteria were suspended in PBS at concentrations of $3 \times 10^{8}$ and $3 \times 10^{6}$ bacteria per ml. Before use, silicon substrates with deposited coatings were rinsed with $70 \%$ ethanol for $20 \mathrm{~s}$ and sterile PBS for $30 \mathrm{~s}$ and then dried in air under sterile conditions.

Silicon substrates affixed to the bottom plate of the parallel plate flow chamber ${ }^{31}$ were exposed to continuous flow of bacterial suspension for $2 \mathrm{~h}$ at a flow rate of $1 \mathrm{ml} \mathrm{min}^{-1}$. Subsequently, unattached bacteria were flushed out by rinsing with PBS buffer for $15 \mathrm{~min}$, and adhering bacteria were stained with live/dead staining (BacLight, Molecular Probes Europe BV, Leiden, The Netherlands). The numbers of live and dead bacteria were determined by fluorescence microscopy (Leica Microsystems BV, Rijswiik, The Netherlands).

\section{Osteoblast experiments}

Osteoblast cell culture. Human fetal osteoblast cells (HFOB 1.19, ATCC no. CRL-11372) were cultured in a 1:1 mixture of Ham's F12 medium (Invitrogen, Grand Island, NY, USA) and Dulbecco's Modified Eagle's medium-low glucose (Cellgro, Portsmouth, NH, USA) supplemented with $1 \%$ penicillinstreptomycin (Sigma-Aldrich, St Louis, MO, USA) and 10\% fetal bovine serum (Atlanta Biologicals, Inc., Flowery Branch, GA, USA). The cells were incubated in a humidified atmosphere of $5 \% \mathrm{CO}_{2}$ at $37^{\circ} \mathrm{C}$. All cells were between 4 and 6 passages.

Osteoblast cell seeding on LbL films. Silicon wafers coated with (MMT/PAA) 9.5 films were disinfected with $70 \%$ ethanol for $1 \mathrm{~h}$ followed by three washes in sterile PBS. These samples were loaded with gentamicin for $2 \mathrm{~h}$. As controls, wafers coated with gentamicin-free (MMT/PAA $)_{9.5}$ films and bare Si wafers were used. All wafers were placed in a 12-well plate, and a volume of $40 \mu \mathrm{l}$ of HFOB cell suspension containing $2 \times 10^{4}$ cells was pipetted onto each wafer. The cells were allowed to attach for $2 \mathrm{~h}$, and then $1 \mathrm{ml}$ of medium was added to each well. The cultures were maintained for 7 days with medium replacement every other day.

Quantification of osteoblast cell numbers on LbL films. Cell numbers were determined using an MTS assay kit (Promega, Madison, WI, USA) after culturing for 1 and 7 days. Briefly, samples were transferred to a fresh 12-well plate. A volume of $200 \mu \mathrm{l}$ of the combined tetrazolium salt (MTS)/phenazine methosulfate solution (20:1) was pipetted into each well containing $1 \mathrm{ml}$ of culture medium. The ratio 20:1 is the ratio of the volumes of MTS to phenazine methosulfate. The plate was then incubated for $2 \mathrm{~h}$ at $37^{\circ} \mathrm{C}$ in a humidified atmosphere containing $5 \% \mathrm{CO}_{2}$. Cell proliferation was expressed as the absorbance at $490 \mathrm{~nm}$ measured using a microplate reader (BioTek, Winooski, VT, USA). Each group was measured in triplicate. The cell number was determined using a standard calibration curve.

Osteoblast cell immunofluorescence staining. Fluorescence staining was performed to observe the formation of actin filaments after 1 and 7 days of cell culture. In brief, cells cultured on LbL nanocomposite coatings were fixed with $4 \%$ paraformaldehyde (Sigma-Aldrich) in PBS at $4{ }^{\circ} \mathrm{C}$ for $30 \mathrm{~min}$. The cells were permeabilized for $5 \mathrm{~min}$ in $1 \%$ Triton X-100 (Sigma-Aldrich) in PBS, followed by blocking with $1 \%$ bovine serum albumin in PBS for $30 \mathrm{~min}$. The cells were then treated for $30 \mathrm{~min}$ with fluorescein isothiocyanate-labeled phalloidin (1:100; Sigma-Aldrich) to stain actin fibers. Images were captured using a Zeiss LSM confocal microscope (North Chesterfield, VA, USA).
Live/dead osteoblast cell viability. Cell viability was quantified using a live/dead cell viability assay kit (Invitrogen) after 1 and 7 days. The cells were stained based on membrane integrity and intracellular esterase activity as per the manufacturer's protocols. Briefly, cell-seeded scaffolds were incubated at room temperature for $30 \mathrm{~min}$ in PBS containing $2 \mu \mathrm{M}$ calcein AM (green) and $4 \mu \mathrm{m}$ ethidium homodimer-1 (red). Cells stained green (live) and red (dead) were imaged using a Zeiss LSM confocal microscope.

\section{Characterization methods}

Zeta potential measurements were carried out for $0.05 \%$ silica particle suspensions using a Zetasizer Nano ZS (Malvern Instruments, Malvern, UK) at $25^{\circ} \mathrm{C}$.

Water contact angle measurements were performed at ambient conditions (temperature, $\sim 22^{\circ} \mathrm{C}$; humidity, $23 \% \mathrm{RH}$ ) using a KSV CAM 101 (KSV Instruments Ltd, Helsinki, Finland).

Confocal laser scanning microscopy imaging of coatings and osteoblasts was performed using a Zeiss LSM 5 PASCAL confocal scanning system (Carl Zeiss MicroImaging Inc., Thornwood, NY, USA) equipped with a C-Apochromat $63 \times 1.2 \mathrm{~W}$ corr water immersion objective. For film visualization, multilayer coatings were immersed into a very dilute Alexa 488 hydrazide sodium salt (Alexa 488, Molecular Probes, Inc., Grand Island, NY, USA) solution. For confocal laser scanning microscopy studies, the hydrogel films deposited at the surface of the Si wafers were placed vertically in a Lab-Tek chamber slide (Sigma-Aldrich). The chambers of the Lab-Tek slide were then sequentially filled with buffer solutions at a certain $\mathrm{pH}$.

Scanning electron microscopy images were obtained using a Zeiss Auriga Dual-Beam FIB-SEM (North Chesterfield, VA, USA). Cross-sectional specimens were prepared by fracturing. Silicon wafers with sample films were fixed to scanning electron microscopy specimen holders with conductive tape. Gold-platinum alloy was sputtered onto sample surfaces with an RF-plasma chamber for $10 \mathrm{~s}$. The applied voltage varied from 1 to $3 \mathrm{kV}$.

Fourier transform infrared spectroscopy (FTIR) analysis was performed on Bruker Tensor-27 (Billerica, MA, USA) spectrometer equipped with an MCT detector and OPUS 6.5 software (Bruker Optics Inc., Billerica, MA, USA). The total number of scans was 256 at $4 \mathrm{~cm}^{-1}$ resolution. Origin Pro 8.0 software (OriginLab Corporation, Northampton, MA, USA) with a curve-fitting procedure was utilized to quantify the amount of released gentamicin.

Atomic force microscopy (AFM) measurements were performed in air at room temperature using a NSCRIPTORdip pen nanolithography system (Nanoink, Chicago, IL, USA) operating in contact mode. AFM measurements of film thicknesses were obtained by scanning the AFM tip over a scratch in the film made with a razor.

Ellipsometry measurements of the thickness of dry polymer-antibiotic films were performed using a homebuilt instrument, assuming a constant film refractive index of 1.5

Statistical analysis. All quantitative data are reported as mean \pm s.d. At least three samples per time point were evaluated for statistical analysis. Significant differences among the groups of scaffolds were determined by performing Student's $t$-test. A confidence interval of $P<0.05$ was considered statistically significant.

\section{RESULTS AND DISCUSSION}

\section{Responsive nanocomposite assemblies}

We first assembled a hydrogel-like LbL matrix for hosting therapeutic molecules. Figure 1 illustrates the direct assembly of MMT platelets with a weak polyanion, PAA, within the LbL films. The success of this assembly is somewhat counterintuitive, as both MMT and PAA carry a negative charge at neutral $\mathrm{pH}$. To circumvent electrostatic repulsion between film components, assembly was performed at $\mathrm{pH} 2.2$, at which PAA carries no negative charge ( $p K_{a}$ of PAA is $\sim 6.8$ ). AFM measurements of film thickness by scanning the AFM tip over a razor scratch in the film confirmed that, similar to other clay-polyelectrolyte multilayers, ${ }^{15,19}$ the dry thickness increased linearly with the number of deposited layers (Figure 1a), suggesting 
a

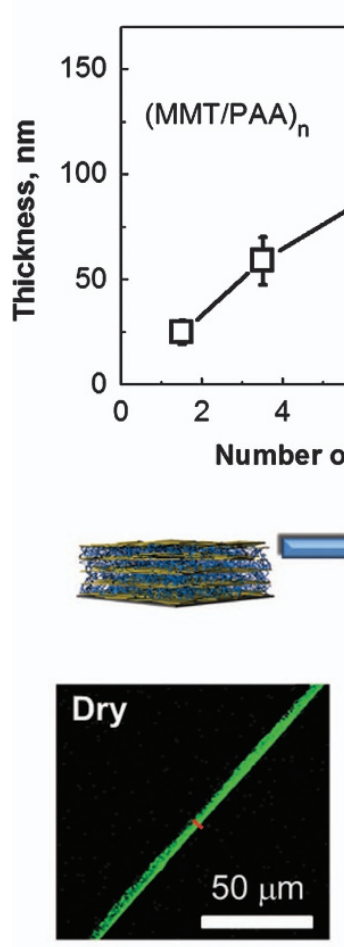

b
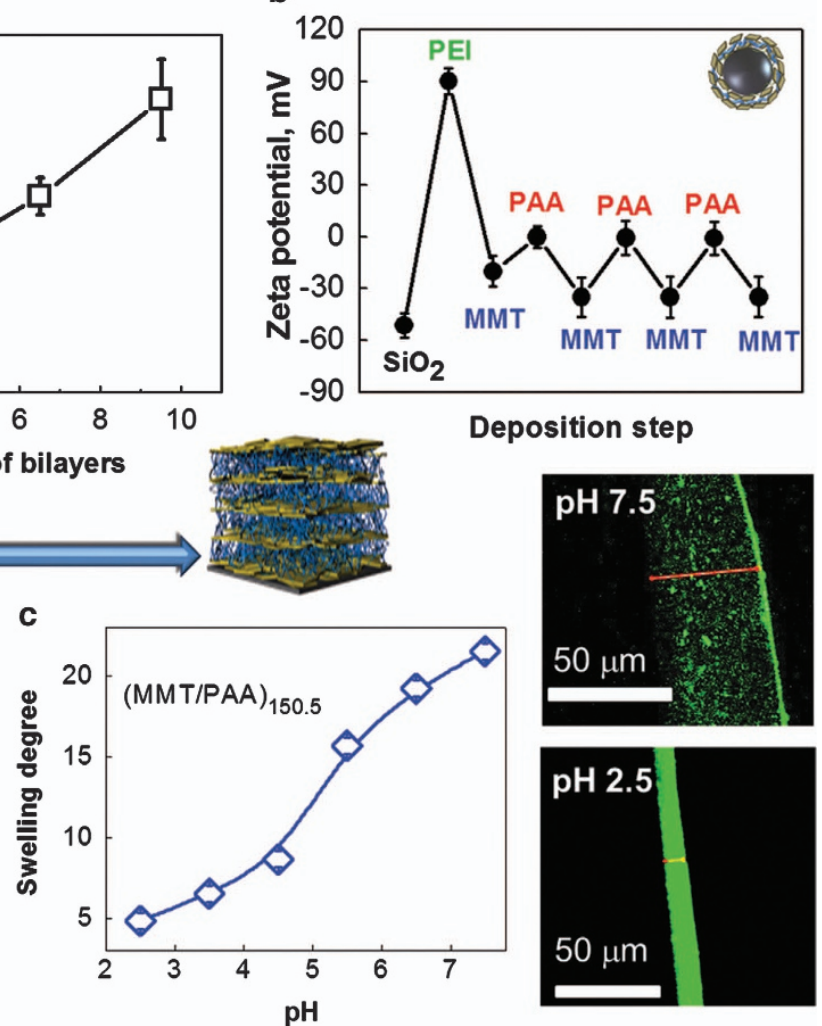

Figure 1 (a) Dry thickness of montmorillonite/polyacrylic acid (MMT/PAA) films determined via atomic force microscopy (AFM) measurements of the height of a razor scratch in a film deposited on an Si wafer; (b) $\zeta$-potentials of a $0.05 \%$ dispersion of $4-\mu$ m-diameter silica particles during sequential deposition

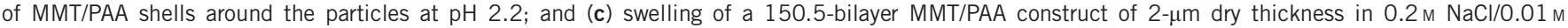
phosphate buffer solutions at various $\mathrm{pH}$ values, as visualized by confocal laser scanning microscopy (CLSM) of Alexa-488-stained films.

a low diffusivity of film components during deposition. The bilayer thickness for the MMT/PAA system of $\sim 15 \mathrm{~nm}$ is not unusual for polyelectrolyte/MMT, for which larger bilayer thicknesses have been reported, ${ }^{32}$ with differential thicknesses of $11 \pm 1 \mathrm{~nm}$ for clay and $4 \pm 1 \mathrm{~nm}$ for PAA. These data suggest the assembly of partially exfoliated MMT platelets ${ }^{7}$ and reflect a loopy conformation of uncharged PAA chains under deposition conditions at $\mathrm{pH} 2.2$. The neutrality of PAA molecules during the assembly conditions follows from $\zeta$-potential measurements, when MMT/PAA shells were constructed around $4-\mu \mathrm{m}$-diameter silica particles at $\mathrm{pH} 2.2$ (Figure $1 \mathrm{~b}$ ). The $\zeta$-potentials oscillated between $\sim-35 \pm 1 \mathrm{mV}$ and $\sim 0 \pm 1 \mathrm{mV}$ for the deposition of the MMT and PAA layers, respectively (see Figure $1 \mathrm{~b}$ ). The linear growth of nanocomposite films was also confirmed by FTIR (Supplementary Figure S1) that showed a linear increase in the intensities of a $1717 \mathrm{~cm}^{-1}>\mathrm{C}=\mathrm{O}$ stretching vibrational band of PAA and several bands assigned to MMT nanosheets (high-intensity $1047 \mathrm{~cm}^{-1}$ band and lower-intensity $1120,922,890,850$ and $800 \mathrm{~cm}^{-1}$ bands) with the number of MMT/PAA bilayers.

MMT/PAA constructs have unprecedented degrees of swelling that has not been previously observed with uncrosslinked LbL films. Figure 1c shows the equilibrated swelling degrees of (MMT/PAA) $)_{150.5}$ films stained with Alexa 488 for visualization by confocal laser scanning microscopy. The swelling kinetics of the MMT/PAA films in solutions at various acidities and the corresponding contact angle changes are shown in Supplementary Figure S2. Even at $\mathrm{pH} 2.5$, where PAA does not carry a charge, the film takes up a large amount of water (swelling degree $\sim 4$ ). At $\mathrm{pH}>2.5$, the water uptake dramatically increases as the PAA becomes more ionized, reaching a swelling degree as high as 23 at $\mathrm{pH} 7.5$.

The like charges of both film components and the stability of the highly hydrated MMT/PAA assemblies are unique features of these films. Although interactions between PAA and MMT solutions have been previously observed in bulk aqueous solutions at low $\mathrm{pH},{ }^{33}$ the assembly of PAA and MMT within LbL constructs usually required the use of a 'binder' polycation layer that had to be alternated between PAA and MMT during the construction of polycation/PAA/ polycation/MMT hybrid films. ${ }^{34}$ To the best of our knowledge, this is the first report of LbL films built solely of like-charged components. Similar to bulk MMT/polymer hydrogels, clay nanoplatelets can be considered as large 'crosslinkers', and a smaller number of crosslinks may be required to stabilize nanocomposite hydrogel structures compared with all-polymer hydrogels. ${ }^{4}$ At the same time, unlike bulk hydrogels, MMT/PAA LbL films are prepared via sequential adsorption from MMT and PAA solutions on a solid; therefore, their structure and composition are governed by different (that is, adsorption) laws than those applicable to their bulk counterparts.

We hypothesize that nanocomposite film components are held together via hydrogen bonding of unionized PAA groups within the basal plane and via electrostatic interactions between charged PAA units and the positively charged edges of MMT nanoplatelets. Whereas MMT nanoplatelets present negative charge at the basal plane, their edges are positively charged in acidic media because of the protonation of $-\mathrm{AlOH}$ groups $\left(p K_{a}\right.$ of $\mathrm{AlOH}_{2}{ }^{+}=\sim 5$ ). In agreement with our hypothesis on the significant role of clay-edge-positive charges, a MMT/PAA assembly could only be constructed at a $\mathrm{pH} \leqslant 4$. In 
addition to ion pairing between PAA and $\mathrm{AlOH}_{2}{ }^{+}$edge groups, assembly may also be driven by dipole-cation interactions between carbonyl groups of PAA and positive edge charges. Remarkably, when assembled under acidic conditions and exposed to high-pH buffer solutions between 2.5 and 8 , nanocomposite films were stable for at least 45 days. At $\mathrm{pH}>8$, however, the films deconstructed as the edge $\mathrm{AlOH}$ and $\mathrm{SiOH}$ groups of MMT nanoplatelets acquired a negative charge $\left(p K_{a}\right.$ of $\mathrm{AlOH}$ and $\left.\mathrm{SiOH}=7.9-8.5\right)$. Thus, although the $\mathrm{pH}$ window for deposition of clay/PAA films was controlled by the $p K_{a}$ of $\mathrm{AlOH}_{2}{ }^{+}$at the edges, the stability of the formed multilayers correlated with the $p K_{a}$ of the $\mathrm{AlOH}$ and $\mathrm{SiOH}$ groups.

The stability and highly open, swollen structure of MMT/PAA assemblies at $\mathrm{pH} 7.5$ are beneficial for the use of these films as matrices to host and release bioactive molecules, such as positively charged antibiotics. We used gentamicin, a broad-spectrum antibiotic clinically used against Gram-positive and Gram-negative bacteria, as a guest molecule for loading within MMT/PAA nanocomposite films. An increase in the dry film thickness (Figures $2 a$ and d) indicated an inclusion of a large amount of antibiotic, that is, $\sim 45 \pm 5 \%$ of the dry matrix thickness of gentamicin within the film corresponded to high loading densities of $\sim 450 \mu \mathrm{g} \mathrm{mm}^{-3}$. The loading was accompanied by an increase in the water contact angle of the 9.5-bilayer nanocomposite matrix from $55 \pm 4^{\circ}$ for as-deposited to $78 \pm 4^{\circ}$ for gentamicin-loaded MMT/PAA films. The cross-sectional SEM images of (MMT/PAA $)_{90.5}$ coatings are consistent with earlier reports of the preferred orientation of clay nanosheets parallel to film surfaces. ${ }^{8,32}$ In addition, the presence of gentamicin within the nanocomposite films was monitored by FTIR using a characteristic vibrational band of gentamicin at $\sim 1557 \mathrm{~cm}^{-1}$ (Figure $2 \mathrm{~b}$ ).
Supplementary Figure S3A shows AFM images of dry (MMT/ PAA) 90.5 films, demonstrating a root-mean-square roughness of $\sim 30 \pm 5 \mathrm{~nm}$ for these $\sim 1.4-\mu \mathrm{m}$-thick films containing MMT platelets within the outermost film layer. The film roughness was almost independent of the number of deposited layers (data not shown). After gentamicin loading, the film roughness remained unchanged (Supplementary Figure S3B), indicating a laterally homogeneous inclusion of gentamicin. Absorption of gentamicin by the highly swollen nanocomposite matrix was accompanied by drastic, 15-fold film deswelling (Figure 2c), that occurred because of a neutralization of the negative charges within the MMT/PAA matrix by ionic pairing with gentamicin molecules. After the uptake of gentamicin, the swollen film thickness comprised 50\% MMT/PAA, 23\% gentamicin and $\sim 27 \%$ water.

Obvious candidates for gentamicin sequestration are the carboxylic groups of the assembled PAA that can form ionic pairs with the protonated amino groups of gentamicin. Basal planes of MMT are also known to bind to positively charged molecules, including cationic antibiotics, via an exchange with native cations. ${ }^{35,36}$ To confirm the binding of gentamicin with MMT nanoplatelets, we directly assembled gentamicin and MMT from $\mathrm{pH} 7.5$ solutions and used these films as a control. Supplementary Figure S4 shows that unlike $(\mathrm{MMT} / \mathrm{PAA})_{n}$ films, the MMT/gentamicin films were very rough (Supplementary Figure S4), suggesting uneven deposition of components. However, these films could be consistently constructed at $\mathrm{pH} 7.5$ and were invariable in their morphology in various buffer solutions. Therefore, we conclude that gentamicin binding occurs with both components of the film (PAA and MMT). However, despite the binding of gentamicin with PAA, films composed solely of PAA a

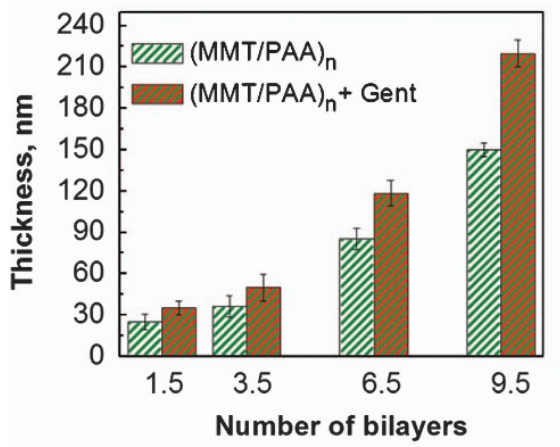

C

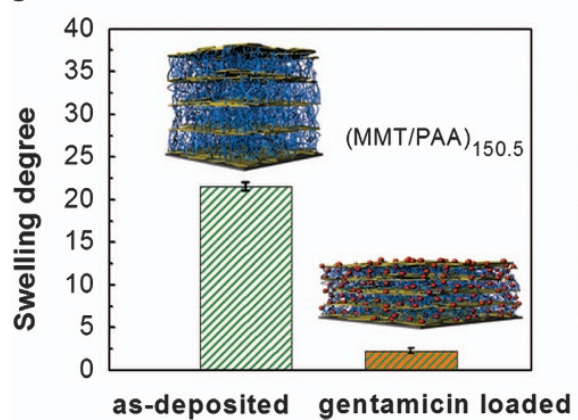

b

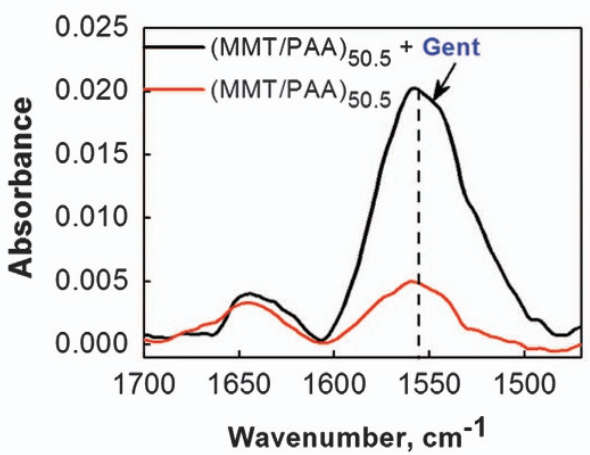

d

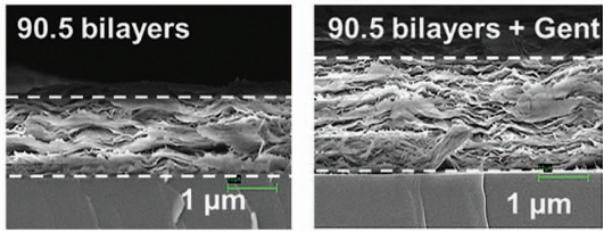


and gentamicin could not be constructed because of solubilization of the adsorbed gentamicin by the excess amounts of PAA added at each sequential deposition step (Supplementary Figure S5).

It was important to probe the long-term behavior of gentamicincontaining films under bacteria-free physiologic conditions, that is, in PBS at $\mathrm{pH}$ 7.5. Most of the currently used antibiotic-containing coatings elute their content as a function of time with a low tail release, contributing to the development of antibiotic-resistant bacterial strains. In contrast, gentamicin-loaded MMT/PAA films showed exceptional stability in $\mathrm{PBS}$ at $\mathrm{pH} 7.5$, and they did not elute measurable amounts of gentamicin for up to 45 days, even when exposed to large volumes of buffer that was refreshed daily (Figure 3). The 45-day stability was also confirmed by the invariability of the AFM-measured dry thickness of the film.

However, when challenged by acidic buffer solutions, gentamicinloaded films released some of the sequestered antibiotic. The amount of gentamicin released was strictly controlled by the environmental $\mathrm{pH}$ and leveled off after $\sim 5 \mathrm{~min}$ with each drop in $\mathrm{pH}$. This suggests that release is determined by the charge balance of gentamicin ionic pairing with PAA units within the film and occurs as ionic pairing is disrupted because of the protonation of PAA in low- $\mathrm{pH}$ solutions. In contrast to our previously reported single-component films of all-polymer chemically crosslinked poly(methacrylic acid) LbL hydrogels, ${ }^{26}$ clay/PAA layers exhibit significantly enhanced retention of antibiotics within the host matrix in salt solutions, most likely because of favorable dipole-dipole interactions of antibiotics with MMT nanoplatelets. Increasingly, large percentages of gentamicin were released from MMT/PAA films in solutions with lower $\mathrm{pH}$, as confirmed by FTIR and AFM (Figures $4 \mathrm{a}$ and $\mathrm{b}$ ). The $\mathrm{pH}$-triggered gentamicin release was also confirmed in experiments with gentamicin-loaded (MMT/PAA) 3.5 films deposited on silica particles, for which the amount of released gentamicin was determined by monitoring the supernatant absorbance of a ninhydrin-gentamicin product (Supplementary Figure S6).

All techniques indicated that even at a $\mathrm{pH}$ as low as 3.5, approximately half of the included gentamicin remained bound within the nanocomposite matrix. Because the control MMT/ gentamicin films did not release gentamicin when the $\mathrm{pH}$ was varied between 3 and 8 (Figure 4a), the released gentamicin accounts for that what was bound with PAA, and the fraction of unreleased gentamicin at $\mathrm{pH} 3.5$ represents that what was sequestered by the MMT nanoplatelets. The presence of two types of antibiotic-binding sites in MMT/PAA nanofilms is advantageous for the antibacterial activity of these coatings, as it supports a dual mechanism of antibacterial defense via a combination of $\mathrm{pH}$-triggered release and contact killing.

After completing gentamicin release at $\mathrm{pH} 3$ and re-exposure to PBS solutions at $\mathrm{pH} 7.5$, the films drastically enhanced their water uptake capability and increased their swelling ratio to $\sim 9$ (Figure $4 \mathrm{c}$ ). Such an increase is a result of $\mathrm{pH}$-induced desorption of gentamicin from the PAA units and its replacement with inorganic counterions. Dissociation of these inorganic counterions from the binding sites led to swelling of the nanocomposite. Postrelease swelling was less pronounced than the initial swelling of the MMT/PAA matrix, and this is probably because of the residual crossbinding of charged gentamicin molecules with PAA and clay nanoplatelets. The $\zeta$-potentials of the MMT/PAA-coated silica particles before and after gentamicin release were also consistent with two types of gentamicin binding within the matrix. An initial, strongly negative $\zeta$-potential of the MMT/PAA coating of the silica particles shifted to almost zero after gentamicin uptake (Figure $4 \mathrm{~d}$ ) and then increased its negativity after the particles were incubated at lower $\mathrm{pH}$ values, separated by centrifugation and redispersed in buffer solutions at $\mathrm{pH} 7.5$ (Figure $4 \mathrm{~d}$ ). More negative $\zeta$-potentials indicate a loss of positively charged gentamicin by the coating after $\mathrm{pH}$-triggered antibiotic release. Concurrently, the $\zeta$-potential does not reach the higher negative values measured with the original unloaded MMT/PAA matrix, indicating partial retention of gentamicin within the coating as a result of strong, $\mathrm{pH}$-independent binding of gentamicin by the MMT platelets.

\section{Inhibition of bacterial growth}

The antibacterial activity of the gentamicin-loaded nanocomposite coatings was then studied by exposing the coatings to $S$. aureus ATCC 12600, S. epidermidis ATCC 14990 and E. coli ATCC 25922. We explored the antibacterial properties of the antibiotic-loaded MMT/PAA films via two types of experiments that employed either Petrifilm agar plating or flow chamber protocols to probe the antibacterial activity. Figure 5 illustrates the bacterial survival during the Petrifilm assay that employed gentamicin-loaded MMT/PAA films with different numbers of bilayers in the nanocomposite matrices. The results are expressed as 'bacterial survival' or 'complete killing' that constitutes a highly stringent, 'binary' evaluation of the coating (Figure 5).

Figure 5 shows that the antibacterial activity of the gentamicinloaded films was remarkably high: even when challenged with such a high bacterial number $-8 \times 10^{7}$ bacteria per $\mathrm{cm}^{2}$ (close to complete bacterial monolayer coverage)—the gentamicin-loaded MMT/PAA a

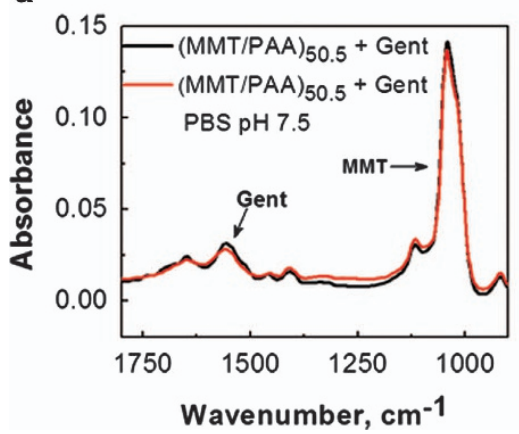

b

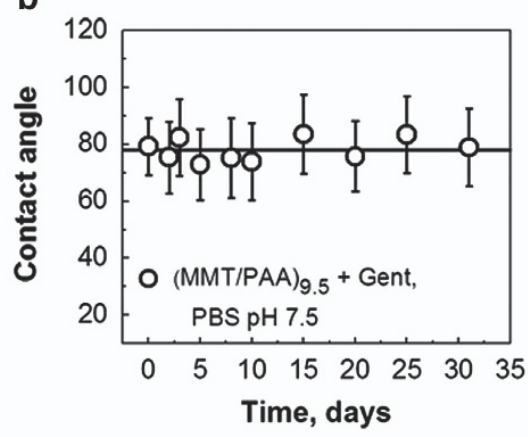

c

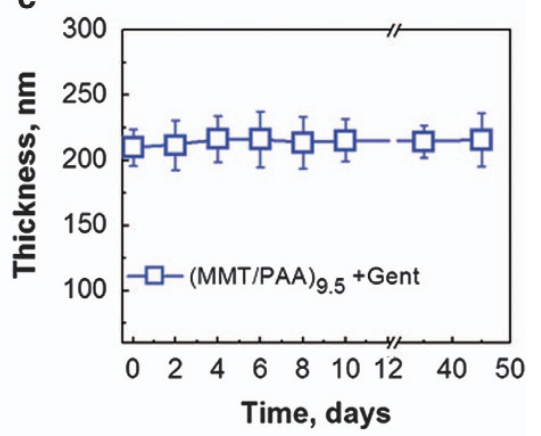

Figure 3 Long-term retention of loaded gentamicin within the montmorillonite/polyacrylic acid (MMT/PAA) films in phosphate buffer solution (PBS) at pH 7.5, monitored via (a) Fourier transform infrared spectroscopy (FTIR) at a 32-day time interval, (b) contact angle measurements and (c) atomic force microscopy (AFM) height measurements with razor-scratched films. 
a

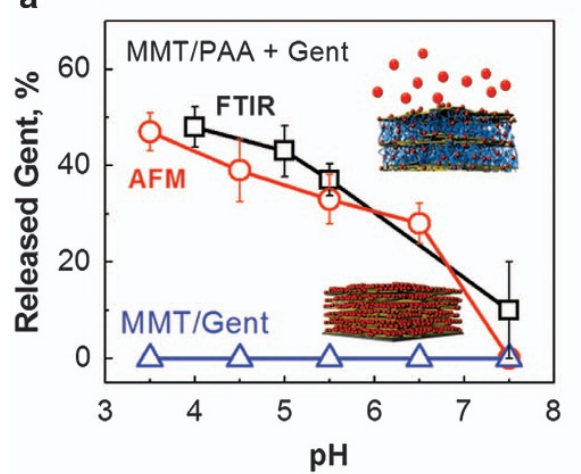

C

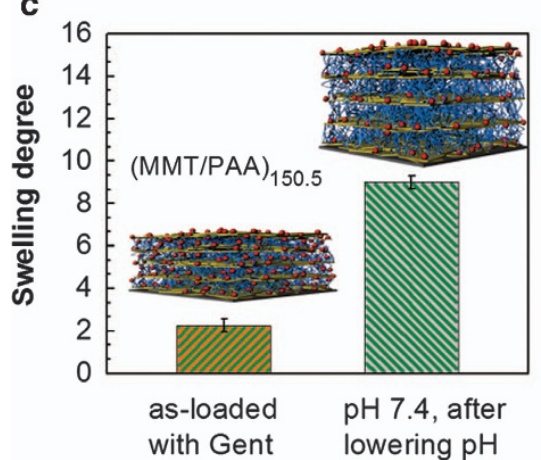

b

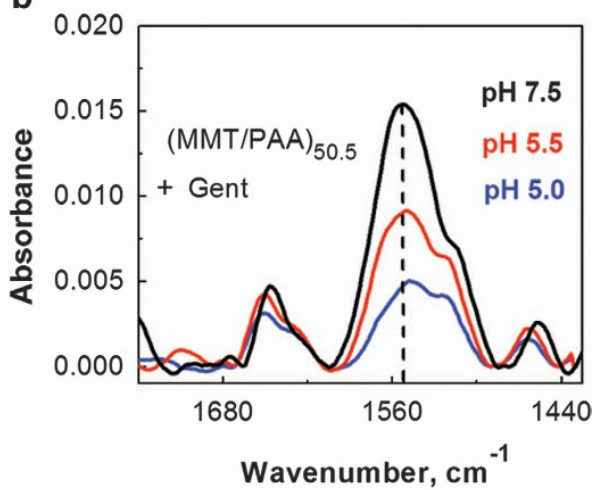

d

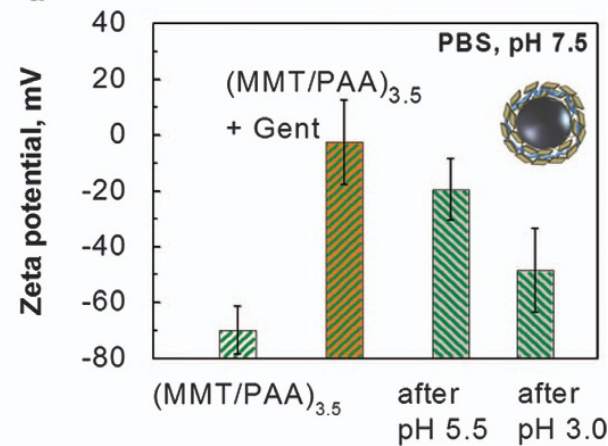

Figure $4(\mathbf{a}, \mathbf{b})$ The $\mathrm{pH}$-triggered release of gentamicin from montmorillonite/polyacrylic acid (MMT/PAA) films deposited on Si wafers. The released amount was calculated from the decrease in film thickness of 3.5-bilayer MMT/PAA or MMT/gentamicin (Gent) films measured by atomic force microscopy (AFM) (a) or by the relative decrease in absorbance of the gentamicin vibrational band at $1517 \mathrm{~cm}^{-1}$ of (MMT/PAA) 50.5 films by Fourier transform infrared spectroscopy (FTIR) (a, b). (c) The swelling of gentamicin-loaded MMT/PAA films (calculated based on the dry thickness of gentamicin-free MMT/PAA matrix) in phosphate buffer solution (PBS) at $\mathrm{pH} 7.5$ before and after releasing gentamicin at $\mathrm{pH}$ 2.5. The thickness of dry gentamicin-loaded $(\text { MMT/PAA })_{150.5}$ films was $\sim 3 \mu \mathrm{m}$. (d) The $\zeta$-potential variations during loading/release of gentamicin from (MMT/PAA) 3.5 films deposited on $4-\mu m-d i a m e t e r$ silica particles that were exposed to $0.2 \mathrm{M} \mathrm{NaCl} / 0.01 \mathrm{M}$ buffer solutions of decreasing $\mathrm{pH}$. All measurements were performed at $\mathrm{pH} 7.5 \mathrm{supported}$ by a $0.01 \mathrm{~m}$ phosphate buffer with $0.2 \mathrm{~m} \mathrm{NaCl}$.

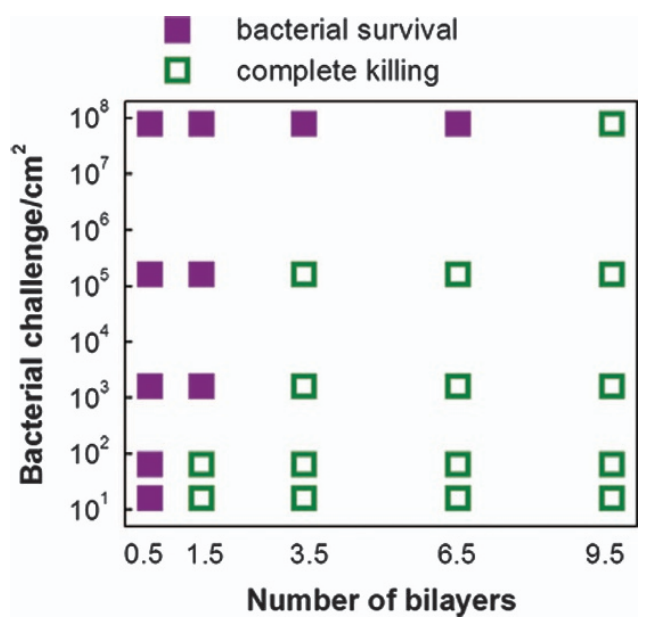

Figure 5 Survival of Staphylococcus aureus ATCC 12600 on gentamicinloaded nanocomposite films as a function of the number of bilayers within the $(\mathrm{MMT} / \mathrm{PAA})_{n}$ coatings. Various bacterial challenges were evaluated. MMT/PAA, montmorillonite/polyacrylic acid.

films containing just 9.5 bilayers (matrix dry thickness of $\sim 140 \mathrm{~nm}$ ) killed all the $S$. aureus. It is also important to highlight the antibacterial activity of the gentamicin-loaded films at the lowest bacterial challenge of only 10 bacteria per $\mathrm{cm}^{2}$, corresponding to a
$10^{-5} \%$ coverage of the surface by bacteria. The antibacterial activity at such a low surface coverage clearly shows that local acidification of the film by a single adhering bacterium induces sufficient gentamicin release for antibacterial activity. To further confirm the film's antibacterial activity and to identify any live bacteria that remained undetected in the Petrifilm assays, samples of (MMT/PAA $)_{n}$ films after the assays with the highest bacterial challenge concentration were immersed in liquid growth media for possible bacterial regrowth at $37^{\circ} \mathrm{C}$. No growth was detected on the 9.5-bilayer gentamicin-loaded MMT/PAA films, confirming complete killing of staphylococci by the antibiotic-loaded matrix. In contrast, gentamicin-loaded films with a smaller number of MMT/PAA bilayers $(n=0.5, n=1.5, n=3.5$ and $n=6.5)$ and gentamicin-free MMT/PAA films exhibited staphylococcal growth. Figure 5 shows that complete killing was dependent on both the staphylococcal concentration and on the number of MMT/PAA bilayers in the nanocomposite matrix. The data clearly show that bacterial survival decreases with an increasing number of MMT/PAA bilayers within the gentamicin-loaded nanocomposite films. This observation suggests that gentamicin loaded within the entire film thickness, rather than only deposited within the film top layers, became bioavailable as a result of the release triggered by the lowered $\mathrm{pH}$ associated with bacterial metabolism. (MMT/Gent) ${ }_{n}$ films ( $n=4,7$ and 10) were much less active and only showed complete killing at smaller bacterial challenges of 80,160 and 1600 bacteria per $\mathrm{cm}^{2}$. Pre-exposure of gentamicin-containing films to PBS 
solutions for 9 days did not negatively affect the antibacterial activity of (MMT/PAA) 9.5 coatings (data not shown).

The Petrifilm assays were also performed with gentamicinloaded coatings using two other bacterial strains: Gram-positive S. epidermidis ATCC 14990 and Gram-negative E. coli ATCC 25922. $(\mathrm{MMT} / \mathrm{PAA})_{9.5}$ coatings completely killed these pathogens at challenges of $1.6 \times 10^{5}$ and $1.6 \times 10^{7}$ bacteria per $\mathrm{cm}^{2}$ (Supplementary Figure S7).

The Petrifilm assays mimic interfacial gaps that are present, for example, between a bone implant and a bone. However, because of the deliberately small fluid volume $(25 \mu \mathrm{l})$ in the assay, these experiments could not elucidate whether bacterially induced, local $\mathrm{pH}$ changes are still effective in a flowing bulk medium. To address this question, we performed bacterial adhesion experiments in a parallel plate flow chamber, assuming that the $\mathrm{pH}$ of flowing bulk medium is not affected by staphylococci on the coating. Figure 6 shows that gentamicin-free MMT/PAA matrices and gentamicinloaded 9.5-bilayer MMT/PAA assemblies induced an approximately fourfold reduction in staphylococcal adhesion compared with control, even under a constant $2 \mathrm{~h}$ flow of concentrated suspensions $\left(3 \times 10^{8}\right.$ bacteria per $\mathrm{ml}$, yielding a surface coverage by staphylococci of $\sim 10 \%$ ) of $S$. aureus at a flow rate of $1 \mathrm{ml} \mathrm{min}^{-1}$. However, a similar observation was made at a 100 -fold lower bacterial concentration $\left(3 \times 10^{6}\right.$ bacteria per $\mathrm{ml}$, corresponding to a surface coverage after $2 \mathrm{~h}$ of flow of $\sim 0.1 \%$ ). The antibacterial efficacy at such a low concentration under flow conditions confirms the conclusion drawn from the Petrifilm assays: acidification by a single adhering staphylococcus induces sufficient local gentamicin release for antibacterial activity. Importantly, the antibacterial activity of the coating in the flow experiment can be enhanced such that an $\sim 15$-fold reduction in staphylococcal adhesion is observed by increasing the number of bilayers within the MMT/PAA matrix to 15.5 (Figure 6a). These results confirm that bacteria can trigger gentamicin release from the nanocomposite coating via highly localized $\mathrm{pH}$ changes in the absence of a $\mathrm{pH}$ change in the bulk fluid surrounding the coating and that these $\mathrm{pH}$ changes induce antibiotic release from the entire film thickness rather than just the film surface.

\section{Cytocompatibility of the coatings}

A combination of antibacterial activity with good tissue-cell integration is a central requirement for the development of the next generation of totally internal implants and devices made from biomaterials. ${ }^{37}$ HFOB cells were used for in vitro cytocompatibility experiments. Figure 7 shows the number of osteoblasts on the left and the cytoskeletal changes in HFOB 1.19 cells on the right. The HFOB 1.19 cells were deposited on gentamicin-free and gentamicin-loaded (MMT/PAA $)_{9.5}$ nanocomposite coatings or on the surface of bare silicon wafers that served as the control.

Compared with Si wafers, the HFOB 1.19 cells for both MMT/PAA groups exhibited a slightly lower increase in cell number $(P<0.05)$ at day 7 that may be attributed to differences in surface chemistry and roughness. The effects of surface chemistry, charge, roughness, stiffness and wettability on cell adhesion and proliferation are well known. ${ }^{38-40}$ For all three substrate types after day 1, HFOB 1.19 cells exhibited a star shape with focal contacts or a spindle shape indicating healthy cells. After 7 days, an increased F-actin density indicated good
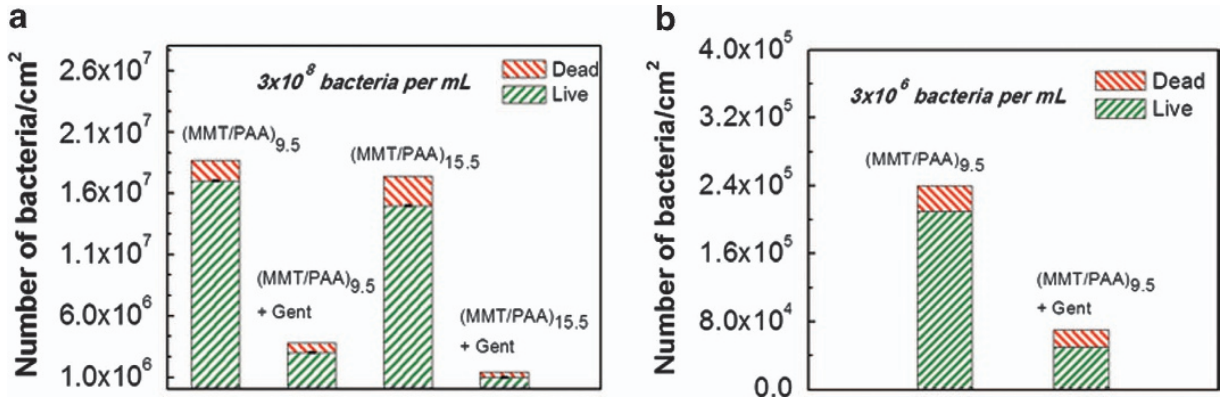

Figure 6 The number of dead and live Staphylococcus aureus ATCC 12600 cells adhering to the surfaces of gentamicin-free and gentamicin-loaded montmorillonite/polyacrylic acid (MMT/PAA) films during a constant 2-h flow of S. aureus ATCC 12600 bacterial suspension at $3 \times 10^{8}$ bacteria per ml (a) and $3 \times 10^{6}$ bacteria per $\mathrm{ml}(\mathbf{b})$ in phosphate buffer solution (PBS) at $\mathrm{pH} 7.5$.

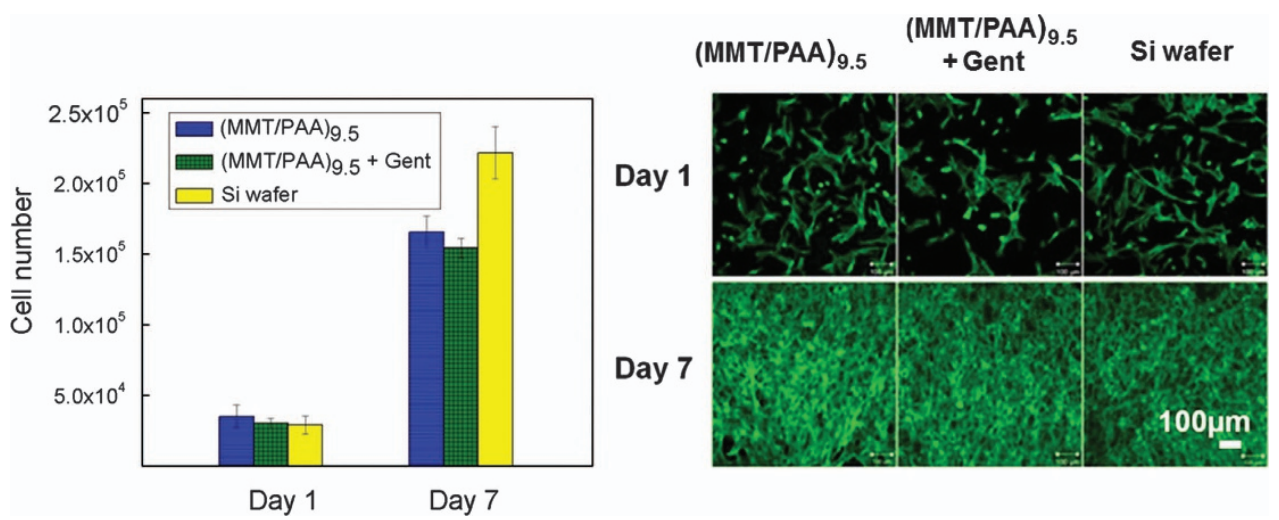

Figure 7 The number of cells derived from an MTS assay (left) and confocal microscopy of cell morphology showing F-actin stress fibers (represented in green) (right) for HFOB 1.19 cell attachment and proliferation on gentamicin-free films, gentamicin-loaded (MMT/PAA) ${ }_{9} 5$ films and the surface of bare silicon wafers. The scale bar in all images is $100 \mu \mathrm{m}$. MMT/PAA, montmorillonite/polyacrylic acid. 
cell proliferation. Live/dead staining of the proliferating cells indicated an overwhelmingly greater number of live cells compared with dead cells (shown in green and red in Supplementary Figure S8, respectively). Overall, the data in Figure 7 and Supplementary Figure S8 illustrate nontoxicity of the coatings and their suitability for implant surface coating in bone.

\section{CONCLUSIONS}

Here, we explored hydrogel-like nanocomposite LbL films as matrices for the controlled sequestration and delivery of antibacterial compounds. The coatings were composed of like-charge polymers and inorganic nanosheets bound together via noncovalent interactions, and they exhibited extremely high degrees of swelling in water. Furthermore, the LbL constructs were mechanically robust because of the presence of clay nanosheets. The nanocomposite films were able to host large amounts of gentamicin, an antibiotic with a broad spectrum of antibacterial activity that is clinically used in local drug delivery systems, that remained safely sequestered and did not elute until the coating was challenged by $\mathrm{pH}$ or bacterial stimuli. This ondemand self-defense strategy minimizes side effects and prevents the continuous elution and low-level tail release of preloaded antibiotics that reduces the risk of developing antibiotic-resistant bacterial strains. Gentamicin-loaded films demonstrated a high efficacy against several types of bacteria known to cause infections associated with medical implants, such as S. aureus, S. epidermidis and E. coli. We suggest that the high efficacy of the coatings is likely a result of the multiresponsive and self-defensive nature of the coatings that provide a multifaceted antibacterial response through a combination of bacteria-triggered release, contact killing and film swelling associated with antibiotic release (provided as an animation in Supplementary Figure S9). These multiple responses were enabled through a synergistic combination of inorganic (clay nanosheets) and organic (weak polyacid) components within the LbL assemblies. Additional advantageous features of the coating include facile control of the total amount of sequestrated and released antibiotic via the number of clay-polymer bilayers assembled within a nanocomposite matrix and the conformal nature of the coatings to substrates of complex shape. Finally, we demonstrated that gentamicin-loaded nanocomposite coatings inhibited bacterial colonization while simultaneously promoting a healthy tissue response. Taken together, these properties make these coatings promising candidates for fighting bacterial infections associated with biomedical and implantable devices.

\section{CONFLICT OF INTEREST}

The authors declare no conflict of interest.

\section{ACKNOWLEDGEMENTS}

We thank Ishan Wathuthanthri at Stevens for his help with the SEM experiments; Li Xu for AFM experiments; Minie Rustema-Abbing, Mary Ann Collins, Michael Hubner, John Hu, Rich Wengenroth and Professor Chang-Hwan Choi for their assistance with bacterial studies and contact angle measurements; and Professor Adriana Compagnoni for useful discussions and help with the animation of the experiments. HJ Busscher is also director of a consulting company, SASA BV (Thesinge, The Netherlands).

1 Vaia, R. A. \& Giannelis, E. P. Polymer nanocomposites: status and opportunities. MRS Bull. 26, 394-401 (2001)

2 Zou, H., Wu, S. \& Shen, J. Polymer/silica nanocomposites: preparation, characterization, propertles, and applications. Chem. Rev. 108, 3893-3957 (2008)

3 Stuart, M. a. C., Huck, W. T. S., Genzer, J., Müller, M., Ober, C., Stamm, M., Sukhorukov, G. B., Szleifer, I., Tsukruk, V. V., Urban, M., Winnik, F., Zauscher, S.,
Luzinov, I. \& Minko, S. Emerging applications of stimuli-responsive polymer materials. Nat. Mater. 9, 101-113 (2010).

4 Haraguchi, K. \& Takehisa, T. Nanocomposite hydrogels: a unique organic-inorganic network structure with extraordinary mechanical, optical, and swelling/de-swelling properties. Adv. Mater. 14, 1120-1124 (2002)

5 Decher, G. Fuzzy nanoassemblies: toward layered polymeric multicomposites. Science 277, 1232-1237 (1997)

6 Lvov, Y., Ariga, K., Ichinose, I. \& Kunitake, T. Formation of ultrathin multilayer and hydrated gel from montmorillonite and linear polycations. Langmuir 12, 3038-3044 (1996).

7 Glinel, K., Laschewsky, A. \& Jonas, A. M. Ordered polyelectrolyte 'multilayers'. 4. Internal structure of clay-based multilayers. J. Phys. Chem. B 106, 11246-11252 (2002).

8 Podsiadlo, P., Kaushik, A. K., Arruda, E. M., Waas, A. M., Shim, B. S., Xu, J., Nandivada, H., Pumplin, B. G., Lahann, J., Ramamoorthy, A. \& Kotov, N. A. Ultrastrong and stiff layered polymer nanocomposites. Science 318, 80-83 (2007).

9 Lutkenhaus, J. L., Olivetti, E. A., Verploegen, E. A., Cord, B. M., Sadoway, D. R. \& Hammond, P. T. Anisotropic structure and transport in self-assembled layered polymerclay nanocomposites. Langmuir 23, 8515-8521 (2007).

10 Li, Y.-C., Schulz, J., Mannen, S., Delhom, C., Condon, B., Chang, S., Zammarano, M. \& Grunlan, J. C. Flame retardant behavior of polyelectrolyte-clay thin film assemblies on cotton fabric. ACS Nano 4, 3325-3337 (2010).

11 Priolo, M. A., Gamboa, D., Holder, K. M. \& Grunlan, J. C. Super gas barrier of transparent polymer-clay multilayer ultrathin films. Nano. Lett. 10, 4970-4974 (2010).

12 Zhuk, A., Mirza, R. \& Sukhishvili, S. Multiresponsive clay-containing layer-by-layer films. ACS Nano 5, 8790-8799 (2011).

13 Chaturbedy, P., Jagadeesan, D. \& Eswaramoorthy, M. pH-Sensitive breathing of clay within the polyelectrolyte matrix. ACS Nano 4, 5921-5929 (2010).

14 Jain, A., Gupta, Y., Agrawal, R., Khare, P. \& Jain, S. K. Biofilms - a microbial life perspective: a critical review. Crit. Rev. Ther. Drug. Carrier. Syst. 24, 393-443 (2007).

15 Campoccia, D., Montanaro, L. \& Arciola, C. R. A review of the biomaterials technologies for infection-resistant surfaces. Biomaterials 34, 8533-8554 (2013).

16 Banerjee, I., Pangule, R. C. \& Kane, R. S. Antifouling coatings: recent developments in the design of surfaces that prevent fouling by proteins, bacteria, and marine organisms. Adv. Mater. 23, 690-718 (2011).

17 Harbers, G. M., Emoto, K., Greef, C., Metzger, S. W., Woodward, H. N., Mascali, J. J., Grainger, D. W. \& Lochhead, M. J. Functionalized poly(ethylene glycol)-based bioassay surface chemistry that facilitates bio-immobilization and inhibits nonspecific protein, bacterial, and mammalian cell adhesion. Chem. Mater. 19, 4405-4414 (2007).

18 Schaer, T. P., Stewart, S., Hsu, B. B. \& Klibanov, A. M. Hydrophobic polycationic coatings that inhibit biofilms and support bone healing during infection. Biomaterials 33, 1245-1254 (2012).

19 Hendricks, S. K., Kwok, C., Shen, M., Horbett, T. A., Ratner, B. D. \& Bryers, J. D. Plasma-deposited membranes for controlled release of antibiotic to prevent bacterial adhesion and biofilm formation. J. Biomed. Mater. Res. 50, 160-170 (2000).

20 Nepal, D., Balasubramanian, S., Simonian, A. L. \& Davis, V. A. Strong antimicrobial coatings: single-walled carbon nanotubes armored with biopolymers. Nano. Lett. 8, 1896-1901 (2008)

21 Lichter, J. A., Van Vliet, K. J. \& Rubner, M. F. Design of antibacterial surfaces and interfaces: polyelectrolyte multilayers as a multifunctional platform. Macromolecules 42, 8573-8586 (2009).

22 Moskowitz, J. S., Blaisse, M. R., Samuel, R. E., Hsu, H.-P., Harris, M. B., Martin, S. D., Lee, J. C., Spector, M. \& Hammond, P. T. The effectiveness of the controlled release of gentamicin from polyelectrolyte multilayers in the treatment of Staphylococcus aureus infection in a rabbit bone model. Biomaterials 31, 6019-6030 (2010).

$23 \mathrm{Li}$, Z., Lee, D., Sheng, X., Cohen, R. E. \& Rubner, M. F. Two-level antibacterial coating with both release-killing and contact-killing capabilities. Langmuir 22, 9820-9823 (2006).

24 Wong, S. Y., Moskowitz, J. S., Veselinovic, J., Rosario, R. A., Timachova, K., Blaisse, M. R., Fuller, R. C., Klibanov, A. M. \& Hammond, P. T. Dual functional polyelectrolyte multilayer coatings for implants: permanent microbicidal base with controlled release of therapeutic agents. J. Am. Chem. Soc. 132, 17840-17848 (2010).

25 Kim, B.-S., Park, S. W. \& Hammond, P. T. Hydrogen-bonding layer-by-layer-assembled biodegradable polymeric micelles as drug delivery vehicles from surfaces. ACS Nano 2, 386-392 (2008).

26 Pavlukhina, S., Lu, Y., Patimetha, A., Libera, M. \& Sukhishvili, S. Polymer multilayers with $\mathrm{pH}$-triggered release of antibacterial agents. Biomacromolecules 11, 3448-3456 (2010).

27 Pavlukhina, S. \& Sukhishvili, S. Polymer assemblies for controlled delivery of bioactive molecules from surfaces. Adv. Drug. Deliv. Rev. 63, 822-836 (2011).

28 Smith, S. M. D-lactic acid production as a monitor of the effectiveness of antimicrobial agents. Antimicrob. Agents Chemother. 35, 237-241 (1991).

29 Andersen, K. B. \& Von Meyenburg, K. Are growth rates of Escherichia coli in batch cultures limited by respiration? J. Bacteriol. 144, 114-123 (1980).

30 Cado, G., Aslam, R., Seon, L., Garnier, T., Fabre, R., Parat, A., Chassepot, A., Voegel, J. C., Senger, B., Schneider, F., Frere, Y., Jierry, L., Schaaf, P., Kerdjoudj, H., Metz-Boutigue, M. H. \& Boulmedais, F. Self-defensive biomaterial coating against bacteria and yeasts: polysaccharide multilayer film with embedded antimicrobial peptide. Adv. Funct. Mater. 23, 4801-4809 (2013)

31 Busscher, H. J. \& van der Mei, H. C. Microbial adhesion in flow displacement systems. Clin. Microbiol. Rev. 19, 127-141 (2006).

32 Tang, Z., Kotov, N. A., Magonov, S. \& Ozturk, B. Nanostructured artificial nacre. Nat. Mater. 2, 413-418 (2003). 
33 Wilson, M. A. \& Lamb, R. N. Interactions of sodium montmorillonite with poly(acrylic acid). J. Colloid Interface Sci. 290, 392-396 (2005).

34 Podsiadlo, P., Michel, M., Critchley, K., Srivastava, S., Qin, M., Lee, J. W. Verploegen, E., Hart, A. J., Qi, Y. \& Kotov, N. A. Diffusional self-organization in exponential layer-by-layer films with micro- and nanoscale periodicity. Angew. Chem. Int. Ed. 48, 7073-7077 (2009).

35 Essington, M. E., Lee, J. \& Seo, Y. Adsorption of antibiotics by montmorillonite and kaolinite. Soil Sci. Soc. Am. J. 74, 1577-1588 (2010).

36 Meng, N., Zhou, N.-L., Zhang, S.-Q. \& Shen, J. Controlled release and antibacterial activity of chlorhexidine acetate intercalated in montmorillonite. Int. J. Pharm. 382, 45-49 (2009).

37 Wang, Y., Libera, M., Busscher, H. J. \& van der Mei, H. C. in Biofilms in Bioengineering. (eds Simoes, M. \& Mergulho, F.) (Nova Science, Commack, 2012).

38 Schneider, G. B., English, A., Abraham, M., Zaharias, R., Stanford, C. \& Keller, J. The effect of hydrogel charge density on cell attachment. Biomaterials 25, 3023-3028 (2004).
39 Richert, L., Engler, A. J., Discher, D. E. \& Picart, C. Elasticity of native and cross-linked polyelectrolyte multilayer films. Biomacromolecules 5, 1908-1916 (2004).

40 Lampin, M., Warocquier-Clérout, R., Legris, C., Degrange, M. \& Sigot-Luizard, M. F. Correlation between substratum roughness and wettability, cell adhesion, and cel migration. J. Biomed. Mater. Res. 36, 99-108 (1997).

(ac)(1)(2) This work is licensed under a Creative Commons Attribution-NonCommercial-ShareAlike 3.0 Unported License. The images or other third party material in this article are included in the article's Creative Commons license, unless indicated otherwise in the credit line; if the material is not included under the Creative Commons license, users will need to obtain permission from the license holder to reproduce the material. To view a copy of this license, visit http://creativecommons.org/licenses/by-nc-sa/3.0/

Supplementary Information accompanies the paper on the NPG Asia Materials website (http://www.nature.com/am) 